\title{
Disidencia sexual y memoria transgeneracional: semiosfera y conservación de la estructura en Opus 123 de Inés Arredondo.
}

\section{Sexual dissidence and transgenerational memory: semiosphere and conservation of the structure in Opus 123 by Inés Arredondo.}

\author{
Claudia Gabriela García Reyes \\ Departamento de Letras / Universidad de Guadalajara (MÉXICO) \\ CE: gabriela.garciareyes@hotmail.com ID ORCID: 0000-0002-1591-3748 \\ Francisco Javier Ponce Martínez \\ Departamento de Letras / Universidad de Guadalajara (MÉXICO) \\ CE: javponce1@hotmail.com ID ORCID: 0000-0003-1831-2232
}

DOI: $10.32870 /$ sincronia.axxiii.n76.33b19

\section{$\mathrm{BY} \cdot \mathrm{NC}$}

Esta obra está bajo una Licencia Creative Commons Atribución-NoComercial 4.0 Internacional

Recibido: 30/03/2019

Revisado: 24/05/2019

Aprobado: $12 / 06 / 2019$

\section{RESUMEN}

Se analiza el cuento "Opus 123", de la escritora mexicana Inés Arredondo siguiendo parte de la metodología del semiólogo ruso luri Lotman. En el texto se aborda, de acuerdo con las categorías de Lotman, la disidencia sexual y en los dos personajes principales masculinos del cuento; además de la memoria transgeneracional en los actantes del texto.

Palabras clave: Inés Arredondo. Análisis semiótico. Homosexualidad. Semiosfera. Memoria transgeneracional. Disidencia. Lotman. 


\begin{abstract}
:
The story "Opus 123" by the Mexican writer Inés Arredondo is analyzed following part of the methodology of the Russian semiologist luri Lotman. The text addresses, according to the categories of Lotman, the sexual dissidence and the two main male characters of the story; besides the transgenerational memory in the actants of the text.
\end{abstract}

Keywords: Inés Arredondo. Semiotic analysis. Homosexuality, Semiosfera. Transgenerational memory. Dissent. Lotman.

La obra de Inés Arredondo (Culiacán, Sinaloa 1928 - Ciudad de México 1989), constituye los cimientos de una literatura enfocada en aspectos que aún hoy en día son mantenidos al margen, puesto que tocan materia de lo prohibido: lujuria, locura, engaño, aborto, erotismo, homosexualidad, muerte; temas que la autora trabajó desde el ángulo más soterrado con la intención de "hablar de lo otro, de lo que generalmente se calla" (Arredondo, 1998, p. 125). Arredondo problematizó tópicos considerados tabú. Su visión nos ofrece una perspectiva donde los contrarios bueno/malo, no son tan claros ni contundentes como comúnmente se piensa. Si bien es cierto que lo anterior ya resulta en una literatura arriesgada que obliga a revisar ciertas situaciones y prejuicios, los cuentos arredondinos ofrecen mucho más. Podemos decir que en ellos existe una historia más o menos coherente con un tiempo y espacio determinado, en la que se imbrica otro relato que se relaciona las más de las veces con aspectos que interpelan a la espiritualidad del hombre, a lo inefable de la existencia humana.

Dentro de las obras de Arredondo con las características antes mencionadas, se sitúa el "Opus 123", texto que se publicó primero de manera aislada en 1983, en la editorial Oasis dentro de la colección Los libros del Fakir, y después en 1988, en el tercer y último libro de cuentos de Arredondo, titulado Los espejos (1988).

"Opus 123" está centrado en dos personajes masculinos dedicados a la música, quienes son aparentemente homosexuales. El relato se ubica en una pequeña ciudad con tintes pueblerinos, en tiempos cercanos a la Revolución Mexicana. Las conductas de los habitantes heterosexuales, 
respecto a la homosexualidad, son de rechazo y marginación, las razones aluden a la constitución ideal del género femenino y masculino, así como a una concepción moral religiosa derivada de la religión católica.

El "Opus 123" cuenta la vida de Feliciano y Pepe, la marginación a la que son sometidos porque no cumplen con la normatividad sexual ni sociocultural de la ciudad de la que forman parte. Ambos personajes son afeminados, además artistas, uno toca el piano y el otro el órgano. Las características particulares que circunscriben a los jóvenes, los hacen doblemente extraños para el resto de los habitantes, pues los vecinos tienen como hábitos y costumbres actividades distintas a las que ellos realizan. En el cuento que se ubica en una pequeña ciudad ${ }^{1}$ de México, los motivos temáticos sexos genéricos y religiosos están articulados por medio de la música. Bajo esa tesitura, la música será tomada en este proyecto de investigación como una figura actancial².

En su mayor parte, el cuento está escrito en tercera persona por un narrador extradiegético, aunque a veces la narración da voz a los personajes introduciendo el diálogo directo. Si bien el narrador no forma parte de la trama, este sí participa en repetidas ocasiones al realizar juicios de valor. La narración se focaliza mayormente en Feliciano y en sus pensamientos, de manera general nos cuenta también sobre la vida de Pepe, y el contexto familiar y sociocultural del que los muchachos son parte.

La ciudad donde viven los personajes principales es presentada como una semiosfera que tiene reglas de conducta social y cultural conservadoras, recordemos que el cuento está ubicado entre los últimos años del siglo XIX y principios del XX. La religión que se profesa en la ciudad, es la católica, misma que se relaciona con los comportamientos y la mentalidad de los personajes. El grado de alfabetización de los habitantes de la ciudad, es evidente por algunos comentarios del

\footnotetext{
${ }^{1}$ La obra menciona la mayoría de las veces que se trata de una pequeña ciudad, aunque también se refiera a ella como un pueblo. La atmósfera tanto geográfica como cultural corresponde más a la segunda. En este trabajo nos referiremos a ella como una ciudad por ser el nombre con el que más veces aparece en el texto.

${ }^{2}$ El actante es un "término tomado de Lucien Tesnière y usado primeramente en la lingüística donde, dentro de cierta concepción de la sintaxis, sirve para denominar al participante (persona, animal o cosa) [conceptos, etc.] en un acto, tanto si lo ejecuta como si sufre pasivamente sus consecuencias... (Beristáin, 2013, p. 5).
} 
narrador: "Nadie sabía explicar cómo era, cómo vivía, en fin, lo que era un gran pianista" (Arredondo, 2011, p. 293).

Lotman considera como una semiosfera a toda esfera que "posee los rasgos distintivos ${ }^{3}$ que se atribuyen a un espacio cerrado en sí mismo. Sólo dentro de tal espacio resultan posibles la realización de los procesos comunicativos y la producción de nueva información" (1996, p. 11). De esta manera, el espacio que configura la pequeña ciudad del "Opus 123", está determinado por la ideología, prácticas sociales, culturales y religiosas.

Las prácticas sistemáticas de una semiosfera son correspondientes a sus rasgos distintivos. En el caso de la obra aquí analizada, decimos que uno de los atributos de la comunidad del "Opus 123", es que es religiosa, pues cumple en la práctica con los sacramentos que la iglesia católica demanda; la sociedad profesa con su hacer, decir y juzgar a lo demás desde ese horizonte.

Focalizados en las conductas de rechazo y desprecio de los habitantes de la pequeña ciudad hacia Feliciano y Pepe, quienes no cumplen con el modelo hegemónico de masculinidad, se evidencia el carácter heteronormativo de la misma ciudad. Paradójicamente, la construcción de la masculinidad ideal en el "Opus 123" se construye a partir de las observaciones y críticas a los jóvenes disidentes y lo que a estos les hace falta para ser considerados "verdaderos" hombres.

Don Feliciano Larrea, el padre de Feliciano, es el personaje que representa la figura del hombre-macho en la pequeña ciudad. Él será el encargado de exigir y después de despreciar a su hijo por su manera de ser físicamente y por la actividad que ha escogido realizar, pues considera que tocar música no es para hombres fuertes:

Un día, en que, intempestivamente, entró don Feliciano Larrea padre a su casa, Josefa Unane lo llamó con cortesía y gracia a que pasara a la sala a escuchar a su hijo tocar nada menos que la Sonata Opus 111 de Beethoven.

El padre gritó:

-iLo que quisiera sería oír una voz fuerte en la fábrica! (Arredondo, 2011, p. 290).

\footnotetext{
${ }^{3}$ Para Lotman toda semiosfera tiene como rasgos distintivos un carácter delimitado e irregular, así como sus características particulares.
} 
El padre asociará en todo momento lo musical con lo homosexual, elementos que serán indisolubles y que se trabajarán más bien como un binomio. Lo cierto es que el recelo y el desprecio por lo homosexual ya eran parte de su imaginario, el detonante para que los sentimientos machistas de don Feliciano salgan, es que ve a su hijo tocar el piano, ejerciendo una práctica que en ese momento era popular entre las señoritas de alcurnia de México, no de varones fuertes y valientes.

No olvidemos que los años en los que está contextualizado el relato, son cercanos a la Revolución Mexicana. La valentía de los hombres es uno de los valores mayormente estimados, incluso se expone la propia vida en batalla, sin saber realmente por lo que se pelea; tal como se cuenta en Los de abajo de Mariano Azuela (1916), y otras novelas que documentan el conflicto social de la Revolución. También es importante señalar que justamente a finales del siglo XIX entra en nuestro vocabulario la palabra "joto", que es usada como calificativo despectivo para señalar a los varones homosexuales. En este periodo, prácticamente hay una persecución de todo aquél varón que pone en duda su virilidad, ejercicio que no terminará hasta la segunda mitad del siglo XX. En La homofobia y sus prejuicios (2012), Monsiváis nos recuerda que:

en la primera mitad del siglo XX y casi hasta la década de $1960 \ldots$ a los homosexuales... se les envía por ejemplo a la cárcel sin procesos... No se les sentencia y no disponen siquiera de abogado defensor de oficio. (2012, p. 26).

Las características de una masculinidad dominante y hegemónica, y la figura del macho, han sido discutidas y analizadas desde diferentes ámbitos de estudio. El filósofo mexicano Samuel Ramos veía que en el mexicano subyace un sentimiento de inferioridad que se manifiesta en "una exagerada preocupación por afirmar su personalidad... [los mexicanos] tienen un afán inmoderado de predominar, de ser en todo los primeros" (Ramos, 1998, p. 51).

La valentía es en la época referida una de las cualidades más apreciadas. Esa "virtud" pasó a formar parte del imaginario popular extendido en el país primero de forma oral en corridos y cantares, y después introducidos en la televisión. Al respecto, Octavio Paz (2004) señala en El laberinto de la Soledad que: 
El ideal de hombría consiste en no 'rajarse' nunca...el 'rajado' es de poco fiar, un traidor o un hombre de dudosa fidelidad...nuestra integridad masculina corre tanto peligro ante la benevolencia como ante la hostilidad...el macho es un ser hermético, encerrado en sí mismo capaz de guardarse y guardar lo que se le confía. (pp. 33-34).

En el "Opus 123", Feliciano y Pepe ponen en duda la fidelidad a la hombría tanto por su afeminamiento como por su práctica artística, lo que se supone que debe hacer un hombre en la pequeña ciudad es parecer físicamente fuerte y dominante, "no rajarse" y hacer labores de "hombres", hombres como los yernos de don Feliciano, no como el "monigote" que para don Feliciano es su hijo: "Haz lo que quieras con tu [...] monigote. A mí no me sirve, yo necesito hombres...." (Arredondo, 2011, p. 292).

Como antes mencionamos don Feliciano relaciona lo homosexual con lo musical, los momentos de mayor agresividad se exponen cuando el hijo entra en contacto con la música.

El desprecio de don Feliciano también alcanza a Pepe, podemos ver esta muestra de violencia articulada nuevamente por medio de la música. El encuentro de don Feliciano y Pepe se realiza porque Pepe ha sido el encargado de tocar la música en las bodas de las hermanas de Feliciano. En la ceremonia todos quedan cautivados por las melodías, y los asistentes ya en la fiesta de celebración preguntan a don Feliciano que quién fue quien tocó el órgano:

Don Feliciano dejó parsimoniosamente la copa sobre la mesa. Se hizo un gran silencio.

-Es un gran organista extranjero que hice venir exclusivamente para estas bodas. No está presente porque, ustedes saben, los artistas son gente extraña que no convive con nosotros los plebeyos-y rio ligeramente. (Arredondo, 2011, p. 299).

Don Feliciano hace llegar a la casa de Pepe "una bolsita de terciopelo negro con una tarjeta que decía: "Para un muchacho de oro estas monedas de oro que heredé de mis antepasados 
'filibusteros'"4 (Arredondo, 2011, p. 300). Por su parte la maestra Unane, que sale indignada de la fiesta junto con la familia de Pepe, va a contarle a Feliciano lo que ha hecho su padre, Feliciano contesta:

-Aguarde un momento ¿Está segura que mi padre obró de esa manera porque Pepe es $[\ldots]$ como yo?

-¿Qué otra razón puede haber? Si hubiera sido Manuelito Lizárraga o Pedrito Marcos, ¿no crees que los hubiera proclamado glorias de la ciudad?. (Arredondo, 2011, p. 303).

Es claro que don Feliciano Larrea no entiende de arte ni de artistas, la sensibilidad que muestra su hijo es suficiente para desestabilizarlo, para sacarlo de su zona de confort, "los artistas son gente extraña" que hay que eliminar del sistema, sobre todo si esos artistas son homosexuales, y si uno de ellos es su hijo.

En "El tema homosexual en dos cuentos mexicanos", las investigadoras de la UAM, Vida Valero y Alejandra Herrera (2001, p. 152), mencionan que para Ortega y Gasset el arte hace sentir al burgués ${ }^{5}$ lo que es: incapaz de cualquier sacramento artístico. Además Feliciano "es el único hijo varón y el padre sabe que nunca continuará con su trabajo, no será capaz de manejar la fábrica... el pianista no cumple así con las expectativas ideales que este burgués quisiera ver en su hijo" (p. 17).

Nosotros observamos que ciertamente hay un desconocimiento y desinterés total por la cultura que supone la música, el padre incluso relaciona la sensibilidad artística con la

\footnotetext{
${ }^{4}$ Cabe destacar que en la cita anterior hay un par de elementos que desde nuestro enfoque funcionan de manera simbólica. Estos elementos agudizan el sentimiento de desprecio, y el mensaje que don Feliciano le manda a Pepe en la tarjeta, junto con los doblones de oro. Según el Diccionario de símbolos de Jean Chevalier y Gheerbrant (1995), se menciona en una de sus acepciones que "...el oro es un tesoro ambivalente. La 'moneda de oro es un signo de perversión y exaltación pura de los deseos'" (1995, p. 786) Mientras que el color negro "es de modo general, el color de la substancia universal...de la materia prima, de la indiferenciación primordial, del caos original...El negro posee indudablemente en este sentido un aspecto de oscuridad e impureza. Pero inversamente es el símbolo superior de la no manifestación y de la virginidad primordial..." (1995, p. 748).

${ }^{5}$ El concepto burgués que trabaja Ortega y Gasset les sirve a las investigadoras en el sentido de que Don Feliciano Larrea cuenta con una buena posición social y económica.
} 
homosexualidad. Advertimos sobre todo, que don Feliciano miente y oculta la prodigiosidad de Pepe en el órgano, porque también hay un desprecio hacia él y su condición de "rajado".

De esa manera vemos que los elementos musicales, y su connotación de sensibilidad, funcionan en el cuento de Arredondo para exhibir los convencionalismos y valores sobre la identidad masculina, entendida en la cultura mexicana.

Como antes mencionamos, la literatura de Arredondo y su grupo de generación tiene una pluralidad de significados, pues los intereses de los escritores fueron diversos. Entre ellos podemos identificar la revisión de los valores al uso. El machismo, tan extendido en nuestro país, asimilado hasta el punto en donde es comprendido como la forma correcta y natural de ser.

Por otro lado, también vemos que al "Opus 123" se trasladan elementos e ideas impuestas por el discurso religioso. Bajo esa perspectiva, los asentimientos y opiniones que desde ahí se realicen sobre la homosexualidad, serán fundamentales en la cosmovisión de comunidades religiosas, en este caso, de estructuras católicas. Antonio Rubio Reyes quien publicó uno de los artículos más recientes sobre el "Opus 123" apunta al respecto de religión-homosexualidad que:

[...] la homofobia se vio reforzada y tuvo una gran difusión con el discurso literario del cristianismo: la Biblia. Apoyados en ella (también en el Corán), la homofobia y el machismo...serán valores bien vistos en distintos lugares del mundo...México al ser un país devoto católico y machista, parte también desde ésta homofobia bíblica enraizada hasta en nuestro lenguaje... (Rubio, 2016, párr. 1).

Vemos pues que la religión opera junto con la construcción hegemónica de masculinidad para limitar las prácticas sexuales de los individuos.

Respecto a las estructuras semióticas, Lotman (1998) señala que en toda semiosfera existen mecanismos que la esfera realiza para autoorganizarse a sí misma, pero en algunos de esos mecanismos hay una negación por aceptar lo extrasistémico, lo que contraviene a lo que la semiosfera considera como normal. En esos casos esa situación habla mal del propio sistema y de 
sus rasgos estructurales pues además se está cortando el dinamismo de los diversos procesos del sistema, como la aceptación de una idea, la incorporación de una actividad, etcétera (págs. 44-48).

En el caso de don Feliciano Larrea es el prejuicio cultural el que impide que acepte la otredad que representa su hijo. Desde nuestro enfoque, apoyados por las teorías de Lotman, advertimos que en el texto hay una crítica a la idiosincrasia tradicionalista que se conforma con los valores y preconcepciones hechos. A los personajes no se les juzga de buenos ni malos, si algo se les reprocha es precisamente su falta de conciencia individual. Don Feliciano no será capaz de cuestionar el ideal de hombría, en cambio actúa en contra de las acciones que realiza su hijo y que contravienen al modelo de masculinidad que hay en la ciudad.

Es notoria la existencia de la marca ideológica heredada de las generaciones previas y que podemos adaptar al concepto que Lotman ha identificado como homeostasis. Dicho proceso cultural de los sistemas, que también está integrado en cierta medida a los rasgos de las esferas que forman las semiosferas, funciona como una memoria transgeneracional por medio de la cual las dinámicas grupales van a relevarse en un sentido cíclico, es la memoria de las experiencias de generaciones pasadas la que en gran medida va a determinar cómo vamos a comportarnos:

Los aspectos semióticos de la cultura (por ejemplo, la historia del arte) se desarrollan, más bien, según leyes que recuerdan las leyes de la memoria, bajo las cuales lo que pasó no es aniquilado ni pasa a la inexistencia, sino que, sufriendo una selección y una compleja codificación, pasa a ser conservado, para, en determinadas condiciones, de nuevo manifestarse. (Lotman, 1998, p. 109).

Así vemos en el "Opus 123" cómo esa memoria transgeneracional impuesta por la religión, cultura y el contexto, condiciona a los habitantes de la ciudad quienes rechazan a los jóvenes por sus características físicas y sus gustos musicales. Sin embargo, como antes mencionamos, estos personajes nunca reflexionan en los motivos de la marginación, ni cuestionan los fundamentos en los que se basan sus juicios, sino que responden de manera inconsciente. 
El proceso, marcha o evolución de la memoria transgeneracional respecto a la homosexualidad en el "Opus 123", es mayormente notorio en la conducta de los compañeros de escuela, quienes a pesar de no comprender completamente lo que dicen, agreden verbalmente a Pepe y Feliciano con adjetivos peyorativos alusivos a su orientación sexual:

Aunque iban a la misma escuela, Pepe Rojas y Feliciano Larrea nunca fueron amigos, lo cual no deja de ser extraño, aunque pensándolo bien, la misma causa que hubiera debido unirlos era la que los separaba, pues ambos sufrían el mismo tipo de cachufletas e insultos.... [Cuando] Pepe recibía un "joto" o un "mariquita" a la pasada, sonreía tontamente...Ninguno de los dos, ni los otros niños comprendían exactamente a qué se referían con aquellas agresiones". (Arredondo, 2011, p. 289).

En este punto del "Opus 123" es visible la relación entre el mecanismo transgeneracional (repetición de la violencia hacia Feliciano y Pepe, los diferentes, aunque, en el caso de los niños ni siquiera saben bien lo que dicen), rasgos distintivos o particulares (heteronormativo, religioso) y prácticas sistemáticas de la semiosfera (marginar, excluir, violentar).

En el apartado sobre la homofobia del Prefacio hacia una agenda de los estudios queer (2009), David Foster señala que la homofobia ${ }^{6}$ es la consecuencia de un miedo irracional hacia la homosexualidad que se canaliza en formas de repudio violento. Agrega que las bases de la práctica homofóbica descansan sobre principios precarios y falaces donde la moral religiosa juega un papel trascendente.

La memoria transgeneracional repite los valores morales del sistema religioso, y algunos de estos valores inciden en el modelo hegemónico de masculinidad. Los sistemas rígidos aunque son dominantes y estructuralmente fuertes, no son invulnerables. Para Lotman (1998, p. 44-48), la autoorganización y posterior autodescripción, son el principio fundamental para generar un cambio en las dinámicas donde el centro de poder de las semiosferas, es el encargado de mantener el orden gracias a esa memoria transgeneracional. De esa manera los elementos que son considerados

\footnotetext{
${ }^{6}$ El concepto homofobia es posterior al momento donde se ubica al cuento, no así la práctica de las conductas en contra de los disidentes sexuales.
} 
por el centro de poder como extrasistémicos y anormales, tomarían valor. Es decir, en el caso del "Opus 123", Feliciano y Pepe tendrían que reconocerse como homosexuales y después establecer comunicación entre ellos y otros que presumiblemente estuviesen en su situación. De igual manera habría que organizarse para comenzar a atender las necesidades que el sistema invisibilizó, además de tomar una postura frente a los sistemas hegemónicos heteronormativos.

Las prácticas autodescriptivas, agrega Lotman (p. 44-48), encierran su propia paradoja, pues en la medida que lo extrasistémico se vuelve sistémico, también puede adquirir los vicios de un sistema. Estos "vicios", no son más que las formas antes descritas: estructuras que se erigen sino como únicas sí como las más importantes, lo que puede ocasionar que se ignoren los subsistemas que quedan al margen o periferias de lo nuclear.

En el "Opus 123", Feliciano y Pepe son presentados como dos personajes ingenuos que descubren que son diferentes porque es el resto de la sociedad quien se los dice, en ese tenor la posibilidad de una autodenominación y posterior autoorganización es un evento remoto.

Esa noche [en la que Josefa Unane recomienda que Feliciano estudie en Viena, y el padre se irrita por ello], insomne y con fiebre, Feliciano pudo oír la voz alta y colérica de su padre. Una frase que le quedó grabada con fuego en la mente: "No vas a dejarme por ese marica, por ese homosexual [...]" No conocía la palabra, pero supo que ella sellaba su destino (Arredondo, 2011, p. 292).

Si bien, en el cuento de Arredondo, la posibilidad de la autodescripción es un evento que no aparece como probable, observamos que a partir de la teorización de los problemas de género -y podríamos decir, de cualquier problemática-, comienzan a visualizarse las necesidades particulares que ya no son cubiertas por el sistema que pretendía estudiarlas.

En ese sentido en este análisis no se considera como negativo la cualidad de lo extrasistémico por buscar su propio sistema, sino que se contempla como un proceso evolutivo que también ha de realizarse a favor del estudio de las características particulares de cada semiosfera. En ese tenor, la propuesta de Lotman que señala (p. 44-48) que la negación de lo sistémico por 
describir lo extrasistémico corta el dinamismo de la semiosfera, se puede analizar también desde la perspectiva de un proceso que favorece a la creación de nuevas semiosferas con intereses y necesidades particulares, es decir, diferentes categorías analizables dentro de un marco genérico que contemple la multiplicidad sexual, aunque por supuesto, en un caso ideal toda semiosfera habría de aceptar el todo de sus partes.

Arredondo no sólo ha profundizado en los temas más polémicos de la existencia humana (locura, aborto, deseo erótico, disidencia sexual), sino que sus textos confrontan igualmente a los fenómenos de carácter social compartidos por una cultura determinada. Los cuentos nos narran lo extraordinario de la vida, aquello "que generalmente se calla", pero también muestran los sistemas y contextos donde esos personajes marcados, habitan. Desde esa perspectiva una interpretación acerca de su obra es que dentro de ellos subyace la intención de desestabilizar a la memoria transgeneracional o por lo menos cuestionarla para ver cómo se reacciona frente a otra posibilidad de realización de los individuos.

Arredondo, junto con los integrantes de la Generación de Medio Siglo, toca y subvierte temas con fuertes cargas ideológicas que confrontan al lector con el sistema de pensamiento hegemónico, en el caso del "Opus 123", como vemos con la heteronormatividad y las identidades genéricas que de ello se desprenden.

\section{Referencias}

Arredondo, I. (1998). Obras completas. En Labastida, C. Ed. México: Siglo XXI.

Arredondo, I. (2011). Cuentos completos. México: Fondo de Cultura Económica.

Beristáin, H. (2013). Diccionario de retórica y poética. México: Porrúa.

Chevalier, J., \& Gheerbrant, A. (1995). Diccionario de los símbolos. Barcelona: Herder.

Foster, D. W. (2009). Ensayos sobre culturas homoeróticas latinoamericanas. Ciudad Juárez, Chihuahua: Universidad Autónoma de Ciudad Juárez.

Lotman, I. M. (1996). La semiósfera I. Semiótica de la cultura y el texto. España: Ediciones Cátedra. 
Lotman, I. M. (1998). La semiósfera II. Semiótica de la cultura, del texto de la conducta y del espacio. España: Ediciones Cátedra.

Monsiváis, C. (2012). La homofobia y sus prejuicios. En J. Coord. Muñóz R., Homofobia, laberinto de ignorancia (pp. 23-32). México: UNAM, Centro de Investigaciones Interdisciplinarias en Ciencias y Humanidades, Colegio de Humanidades.

Paz, O. (2004). El laberinto de la soledad. México: Fondo de Cultura Económica.

Ramos, S. (1998). El perfil del hombre y la cultura en México. México: Planeta Mexicana.

Rubio, A. (Noviembre-Diciembre, 2016). Retrato y desprecio de la homofobia tradicional: "Opus 123 de Inés Arredondo. Los Heraldos Negros: Revista de creación literaria y análisis político, 21(2). Recuperado de http://heraldosnegros.org/retrato-y-desprecio-de-la-homofobia/

Vida, V., \& Herrera, A. (2001). El tema homosexual en dos cuentos mexicanos. Tema y variaciones de literatura (17), 145-162. Obtenido de http://zaloamati.azc.uam.mx/handle/11191/1610 